\title{
Influenza vaccine effectiveness in reducing severe outcomes over six influenza seasons, a case-case analysis, Spain, 2010/11 to 2015/16
}

Pere Godoy ${ }^{1,2,3}$, Arantxa Romero², Núria Soldevila ${ }^{2,4}$, Nuria Torner ${ }^{1,2,4}$, Mireia Jané ${ }^{1,2}$, Ana Martínez ${ }^{1,2}$, Joan A Caylà5, Cristina

Rius $^{2,6}$, Angela Domínguez ${ }^{2,4}$, The Working Group on Surveillance of Severe Influenza Hospitalized Cases in Catalonia ${ }^{7}$

1. Agència de Salut Pública de Catalunya, Barcelona, Spain

2. CIBER Epidemiología y Salud Pública, Barcelona, Spain

3. IRBLleida. Institut de Recerca Biomèdica de Lleida, Lleida, Spain

4. Universitat de Barcelona, Barcelona, Spain

5. TB Research Unit Foundation (fuiTB), Barcelona, Spain

6. Agència de Salut Pública de Barcelona, Barcelona, Spain

7. The Working Group on Surveillance of Severe Influenza Hospitalized Cases in Catalonia have been listed at the end of this article

Correspondence: Pere Godoy (pere.godoy@gencat.cat)

Citation style for this article:

Godoy Pere, Romero Arantxa, Soldevila Núria, Torner Nuria, Jané Mireia, Martínez Ana, Caylà Joan A, Rius Cristina, Domínguez Angela, The Working Group on Surveillance of Severe Influenza Hospitalized Cases in Catalonia. Influenza vaccine effectiveness in reducing severe outcomes over six influenza seasons, a casecase analysis, Spain, 2010/11 to 2015/16. Euro Surveill. 2018;23(43):pii=1700732. https://doi.org/10.2807/1560-7917.ES.2018.23.43.1700732

Introduction: When influenza vaccination is ineffective in preventing influenza virus infection, it may still reduce the severity of influenza-associated disease. Here, we estimate the effect of influenza vaccination in preventing severe outcomes e.g. intensive care unit (ICU) admission and death, even though it did not prevent influenza virus infection and subsequent hospitalisation. Methods: An observational case-case epidemiological study was carried out in 12 sentinel hospitals in Catalonia (Spain) over six influenza seasons 2010/11-2015/16. Cases were individuals with severe laboratory-confirmed influenza virus infection and aged 18 years and older. For each reported case we collected demographic, virological and clinical characteristics. Logistic regression was used to estimate the crude, adjusted odd ratios (aOR) and $95 \%$ confidence intervals (CI). Results: Of 1,727 hospitalised patients included in the study, 799 were female (46.7\%), 591 (34.2\%) were admitted to the ICU and 223 $(12.9 \%)$ died. Influenza vaccination uptake was lower in cases that required ICU admission or died $(21.2 \%$ vs $29.7 \%, p<0.001)$. The adjusted influenza vaccination effectiveness in preventing ICU admission or death was $23 \%$ ( $95 \% \mathrm{Cl}: 1$ to 40 ). In an analysis restricted to sex, age group and antiviral treatment, influenza vaccination had a positive effect on disease severity in all age groups and categories. Conclusions: We found that influenza vaccination reduced the severity of disease even in cases where it did not prevent infection and influenza-associated hospitalisation. Therefore, increased vaccination uptake may reduce complications, ICU admission and death.

\section{Introduction}

Each year, $5-20 \%$ of the global population are infected by the influenza virus, which is estimated to result in 3-5 million cases of severe illness and 300,000 to 500,000 deaths worldwide [1].

Influenza surveillance is essential to determine the timing and spread of influenza and trace variations in circulating influenza viruses to provide information on the composition of the seasonal influenza vaccine [2]. Sentinel surveillance of patients hospitalised due to severe laboratory-confirmed influenza has shown that influenza is an important cause of severe illness and death, mainly among those aged 65 years and older and patients with underlying chronic diseases [3].

The influenza vaccine is the best tool for the prevention of influenza and its complications, particularly in patients with underlying chronic diseases and those aged 65 years and older [4-7]. Influenza vaccination is effective in preventing primary healthcare visits and hospital admissions for laboratory-confirmed influenza [8], but chronic conditions and other risk factors, including older ages, may interfere with and hinder a successful vaccine response $[9,10]$.

When influenza vaccination is ineffective in preventing influenza virus infection it may still have an additional effect by reducing the severity of influenza [11]. It has been suggested that while protection against influenza virus infection is primarily mediated through the antibody response, protection against severe outcomes is mediated through cellular immune responses affecting 


\section{Box}

Influenza-like-illness case definition, Catalonia, Spain, influenza seasons 2010/11-2015/16

Influenza-like-illness (ILI) was defined as a combination of the following three criteria:

(i) Sudden symptom onset:

(ii) $\geq 1$ of the following symptoms:

- fever $\left(\geq 38^{\circ} \mathrm{C}\right)$

- headache

- myalgia or malaise

and

(iii) $\geq 1$ of the following respiratory symptoms:

- cough

- sore throat or

- shortness of breath (dyspnea).

viral clearance $[4,11]$; however, the effect of influenza vaccination on influenza severity remains uncertain. While some studies evaluating hospital admission in patients with laboratory-confirmed influenza have failed to demonstrate a protective effect of influenza vaccination $[12,13]$, others have found it has an effect on reducing influenza severity [14]. Case-case studies are considered the best approach to estimate a net effect of influenza vaccination on the post-infection outcomes only in subjects who become infected [15].

In 2010, Catalonia, a region in the north-east of Spain with 7.5 million inhabitants, initiated surveillance of patients hospitalised due to laboratory-confirmed influenza with the aim of (i) estimating the severity of seasonal influenza epidemics according to the characteristics of the influenza virus, (ii) identifying risk groups for severity and, (iii) providing information to improve influenza prevention and control. The system includes 12 hospitals covering 4,644,543 persons $(62 \%$ of the entire population) [16]. The surveillance system reports on patients hospitalised with severe laboratory-confirmed influenza admitted to one of these hospitals every influenza season since 2010/11. The hospital-based surveillance was set up to supplement the information provided by the influenza sentinel surveillance system based on surveillance information from primary healthcare network physicians [16].

The presented study aimed to estimate the effect of influenza vaccination during influenza seasons 2010/11-2015/16 in preventing severe outcomes, e.g. intensive care unit (ICU) admission and death, when the influenza vaccination did not prevent influenza and subsequent hospitalisation.

\section{Methods}

We conducted a hospital-based observational casecase epidemiological study on the effect of influenza vaccination in reducing disease severity in patients hospitalised due to laboratory-confirmed influenza over six influenza seasons (2010/11-2015/16).

\section{Study population and data collected}

The study population were all reported cases that were those 18 years and older that had been hospitalised with severe laboratory-confirmed influenza virus infection in the 12 sentinel hospitals in Catalonia during six influenza seasons (2010/11-2015/16).

We included patients that had been hospitalisedfor more than 24 hours in any of the 12 participating hospitals due to influenza-like-illness (ILI) with symptom onsetmore than 7 days before admittance. Definition for ILI based on the European Union case definition [17] can be seen in Box.

Patients were recruited in one of the participating hospitals by a sentinel physician who screened all patients admitted overnight presenting with severe ILI. All patients had a nasopharyngeal or throat swab (bronchoalveolar lavage fluid or tracheal aspirate for ICU patients) and influenza virus infection was detected using reverse transcription polymerase chain reaction (RT-PCR).

Public health officers from the surveillance units in Catalonia, collected data from each reported case by interview using a structured questionnaire from the epidemiological surveillance network. Information included socio-demographic data, obesity (body mass index $(\mathrm{BMI})>40)$, pregnancy, major chronic conditions (e.g. asthma, chronic obstructive pulmonary disease (COPD), chronic renal disease, immunodeficiency (HIV infection or other), chronic cardiovascular disease, chronic liver disease).

In addition, information on the laboratory diagnosis, symptom onset, hospital admission and discharge dates, complications (primary or secondary pneumonia with or without bacterial coinfection, respiratory distress syndrome or multiple organ failure), antiviral treatment, influenza vaccination status and date of administration, ICU admission, and death were collected from medical records for all reported cases.

\section{Laboratory data}

Patient samples were first tested for type of virus in the laboratories of the participating hospitals using an in-house real-time influenza A and B PCR after manual nucleic acid extraction. Amplification was performed in an $\mathrm{ABI} 7500$ thermocycler. All samples, including those with unsubtyped influenza virus, were sent to the Catalan Influenza Reference Centre (Hospital Clinic, Barcelona, Spain) to determine the subtype. Samples found to be positive in the reference centre were molecularly subtyped for viruses known to be circulating at 
TABLE 1

Characteristics of patients hospitalised due to laboratory-confirmed influenza, Catalonia, influenza seasons 2010/11-2015/16 $(\mathrm{n}=1,711)$

\begin{tabular}{|c|c|c|c|c|c|c|c|}
\hline \multirow{2}{*}{ Characteristics } & \multicolumn{2}{|c|}{ Total } & \multicolumn{2}{|c|}{ Vaccinated } & \multicolumn{2}{|c|}{ Unvaccinated } & \multirow{2}{*}{$p$ value } \\
\hline & $\mathrm{n}$ & $\%$ & $\mathrm{n}$ & $\%$ & $\mathrm{n}$ & $\%$ & \\
\hline All cases & 1,711 & 100 & 450 & 100 & 1,261 & 100 & NA \\
\hline \multicolumn{8}{|l|}{ Sex } \\
\hline Male & 975 & 57 & 264 & 58.7 & 711 & 56.4 & \multirow{2}{*}{0.401} \\
\hline Female & 736 & 43 & 186 & 41.3 & 550 & 43.6 & \\
\hline \multicolumn{8}{|l|}{ Age } \\
\hline $18-64$ & 799 & 46.7 & 71 & 15.8 & 728 & $57 \cdot 7$ & \multirow{2}{*}{$<0.001$} \\
\hline$\geq 65$ & 912 & $53 \cdot 3$ & 379 & 84.2 & 533 & 42.3 & \\
\hline \multicolumn{8}{|l|}{ Type of influenza virus } \\
\hline A & 1,470 & 85.9 & 375 & 83.3 & 1,095 & 86.8 & \multirow{2}{*}{0.067} \\
\hline $\mathrm{B}$ & 241 & 14.1 & 75 & 16.7 & 166 & 13.2 & \\
\hline \multicolumn{8}{|l|}{ Comorbidities } \\
\hline Obesity (BMI > 40) & 181 & 10.6 & 50 & 11.1 & 131 & 10.4 & 0.669 \\
\hline COPD & 441 & 25.8 & 159 & $35 \cdot 3$ & 282 & 22.4 & $<0.001$ \\
\hline Diabetes mellitus & 425 & 24.8 & 156 & 34.6 & 269 & 21.3 & $<0.001$ \\
\hline Chronic renal disease & 235 & 13.7 & 94 & 28.9 & 141 & 11.2 & $<0.001$ \\
\hline Immunodeficiency & 333 & $19 \cdot 5$ & 74 & 16.4 & 259 & 20.5 & 0.060 \\
\hline Chronic cardiovascular disease & 504 & 29.5 & 202 & 44.9 & 302 & 23.9 & $<0.001$ \\
\hline Chronic liver disease & 112 & 6.5 & 21 & $4 \cdot 7$ & 91 & 7.2 & 0.063 \\
\hline \multicolumn{8}{|l|}{ Complications } \\
\hline Pneumonia & 1,277 & $74 \cdot 9$ & 316 & 70.2 & 961 & 76.2 & 0.016 \\
\hline ARD & 1,019 & 60.8 & 144 & 32.0 & 513 & 40.7 & 0.001 \\
\hline Multi-organ failure & 176 & 10.6 & 40 & 8.9 & 136 & 10.8 & 0.270 \\
\hline ICU admission & 591 & $34 \cdot 5$ & 108 & 24.0 & 483 & 38.3 & $<0.001$ \\
\hline Death & 223 & 13.0 & 63 & 14.0 & 160 & 12.7 & 1.533 \\
\hline Pregnancy $^{a}$ & 26 & 1.5 & 0 & 0.0 & 26 & 2.1 & $\mathrm{NC}$ \\
\hline
\end{tabular}

ARD: Acute respiratory distress; BMI: body mass index; COPD: chronic obstructive pulmonary disease; ICU: intensive care unit; NA: not applicable; NC: not calculable.

aPregnancy was not considered a complication and was in another category.

the time, namely type A (subtypes H1N1pdmog and $\mathrm{H}_{3} \mathrm{~N}_{2}$ ) and type B. Molecular subtyping was used to determine the $\mathrm{H}$ subtype for influenza $\mathrm{A}$ and the lineage for influenza B. Subtyping failed in some cases due to a low viral load and such samples were classified as 'unidentifiable'.

\section{Statistical analysis}

We compared hospitalised cases of severe influenza who required ICU admission or those who died at the hospital after being admitted, with hospitalised cases of severe influenza that did not require ICU admission and did not die. We compared baseline characteristics and vaccination status between the two groups. The baseline variables considered were: sex, age (18-64 years, and those aged 65 years and older), virus (sub) types, major chronic conditions, pregnancy, complications and antiviral treatment. The chi-squared test and Fisher's exact test were used for categorical variables and the t-test for continuous variables for comparisons between the groups.
To investigate relationships between the dependent variables (ICU admission or death) and the independent variables studied (including influenza vaccination), a case-case bivariate analysis was conducted. Possible interactions between influenza vaccination status and any independent variable were analysed by logistic regression. Independent variables were checked for collinearity using the variance inflation factor (Katz).

The effectiveness of influenza vaccination was calculated using the formula vaccine effectiveness $(\mathrm{VE})=(1-$ odds ratio $) \times 100$. Logistic regression was used to estimate the crude and adjusted odds ratios (aOR) and their corresponding 95\% confidence intervals $(\mathrm{Cl})$. A multivariate analysis was performed using the change-in-estimate criterion, including potential confounders in the model when the OR changed $b y \geq 10 \%$. Since influenza vaccination rates among those aged 65 years and older were high and increased substantially with age, to account for dissimilar distributions of baseline characteristics between vaccinated and unvaccinated groups and to reduce confounding, 
TABLE 2

Factors associated with intensive care unit admission and death, Catalonia, influenza seasons 2010/11-2015/16 $(\mathrm{n}=1,727)$

\begin{tabular}{|c|c|c|c|c|c|c|c|}
\hline \multirow[t]{2}{*}{ Characteristics } & \multicolumn{2}{|c|}{$\begin{array}{l}\text { ICU/death } \\
(n=692)\end{array}$} & \multicolumn{2}{|c|}{ Non-ICU/death $(n=1,035)$} & \multirow[t]{2}{*}{ Crude OR } & \multirow[t]{2}{*}{$95 \% \mathrm{Cl}$} & \multirow[t]{2}{*}{$p$ value } \\
\hline & $\mathrm{n}$ & $\%$ & $\mathrm{n}$ & $\%$ & & & \\
\hline \multicolumn{8}{|l|}{ Seasonal vaccination } \\
\hline Yes & 146 & 21.3 & 304 & 29.7 & 0.64 & (o.51 to 0.80 ) & 0.001 \\
\hline No & 540 & 78.7 & 721 & 70.3 & \multicolumn{3}{|c|}{ Ref } \\
\hline \multicolumn{8}{|l|}{ Age } \\
\hline $18-64$ years & 386 & 55.8 & 422 & 40.8 & \multicolumn{3}{|c|}{ Ref } \\
\hline$\geq 65$ years & 306 & 44.2 & 613 & 59.2 & 0.55 & (o.45 to 0.66$)$ & $<0.001$ \\
\hline \multicolumn{8}{|l|}{ Sex } \\
\hline Male & 271 & 39.2 & 472 & 45.6 & 0.77 & (o.63 to 0.93 ) & 0.008 \\
\hline Female & 421 & 60.8 & 563 & 54.4 & \multicolumn{3}{|c|}{ Ref } \\
\hline \multicolumn{8}{|l|}{ Type of virus } \\
\hline A & 602 & 87 & 883 & 85.3 & 1.15 & (o.87 to 1.52$)$ & 0.325 \\
\hline $\mathrm{B}$ & 90 & 13 & 152 & 14.7 & \multicolumn{3}{|c|}{ Ref } \\
\hline \multicolumn{8}{|l|}{ COPD } \\
\hline Yes & 187 & 27.0 & 255 & 24.6 & 1.13 & (o.91 to 1.41$)$ & 0.27 \\
\hline No & 505 & 73.0 & 780 & 75.4 & \multicolumn{3}{|c|}{ Ref } \\
\hline \multicolumn{8}{|l|}{ Obesity } \\
\hline Yes & 87 & 12.6 & 95 & 9.2 & 1.42 & (1.04 to 1.94$)$ & 0.02 \\
\hline No & 605 & 87.4 & 940 & 90.8 & \multicolumn{3}{|c|}{ Ref } \\
\hline Diabetes mellitus & & & & & & & \\
\hline Yes & 170 & 24.6 & 261 & 25.2 & 0.97 & (o.77 to 1.21 ) & 0.76 \\
\hline No & 522 & 75.4 & 774 & 74.8 & & Ref & \\
\hline Chronic renal disease & & & & & & & \\
\hline Yes & 100 & 14.5 & 136 & 13.1 & 1.12 & (o.84 to 1.47 ) & 0.44 \\
\hline No & 592 & 85.5 & 899 & 86.9 & & Ref & \\
\hline Immunodeficiency & & & & & & & \\
\hline Yes & 159 & 23.0 & 177 & 17.1 & 1.45 & (1.14 to 1.84$)$ & 0.003 \\
\hline No & 533 & 77.0 & 858 & 82.9 & & Ref & \\
\hline Chronic cardiovascula & & & & & & & \\
\hline Yes & 196 & 28.3 & 312 & 30.1 & 0.92 & (o.74 to 1.13 ) & 0.42 \\
\hline No & 496 & 71.7 & 723 & 69.9 & & Ref & \\
\hline Chronic liver disease & & & & & & & \\
\hline Yes & 58 & 8.4 & 55 & 5.3 & 1.63 & (1.11 to 2.39$)$ & 0.01 \\
\hline No & 634 & 91.6 & 980 & 94.7 & & Ref & \\
\hline Pregnancy & & & & & & & \\
\hline Yes & 16 & 2.3 & 10 & 1.0 & 2.43 & (1.09 to 5.38$)$ & 0.03 \\
\hline No & 676 & 97.7 & 1025 & 99.0 & & Ref & \\
\hline NI treatment & & & & & & & \\
\hline Yes & 635 & 91.8 & 942 & 91.0 & 1.10 & (o.78 to 1.55 ) & 0.59 \\
\hline$\leq 48$ h symptom onset & 154 & 23.1 & 283 & 28.4 & 0.89 & (o.6o to 1.30 ) & 0.54 \\
\hline$>48 \mathrm{~h}$ symptom onset & 455 & 68.3 & 619 & 62.2 & 1.20 & (o.84 to 1.70 ) & 0.31 \\
\hline No & 57 & 8.6 & 93 & 9.3 & & Ref & \\
\hline Number of risk factors & & & & & & & \\
\hline 0 & 172 & 24.9 & 270 & 26.1 & 0.78 & (o.58 to 1.06$)$ & 0.11 \\
\hline 1 & 241 & 34.8 & 378 & 36.5 & 0.78 & (o.59 to 1.04$)$ & 0.09 \\
\hline 2 & 155 & 22.4 & 235 & 22.7 & 0.81 & (o.62 to 1.10 ) & 0.18 \\
\hline$>2$ & 124 & 17.9 & 152 & 14.7 & & Ref & \\
\hline Hospital stay & & & & & & & \\
\hline $0-7$ days & 145 & 21 & 539 & 52.1 & 0.24 & (0.197 to 0.30$)$ & $<0.001$ \\
\hline$>7$ days & 545 & 79 & 145 & 21 & & Ref & \\
\hline Hospital stay & & & & & & & \\
\hline $0-14$ days & 335 & 48.6 & 859 & 83 & 0.19 & (0.15 to 2.41$)$ & $<0.001$ \\
\hline$>14$ days & 355 & 51.4 & 176 & 17 & & Ref & \\
\hline
\end{tabular}

$\mathrm{Cl}$ : confidence interval; COPD: chronic obstructive pulmonary disease; ICU: intensive care unit; NI: Neuraminidase inhibitors; OR: odds ratio; Ref: reference. 
TABLE 3

Effect of influenza vaccination in reducing severe outcomes in patients hospitalised due to laboratory-confirmed influenza, Catalonia, Spain, influenza seasons 2010/11-2015/16 ( $\mathrm{n}=1,727)$

\begin{tabular}{|c|c|c|c|c|c|c|c|}
\hline \multirow[t]{2}{*}{ Characteristics } & \multicolumn{2}{|c|}{$\begin{array}{l}\text { ICU/death } \\
(n=692)\end{array}$} & \multicolumn{2}{|c|}{ Non-ICU/death $(n=1,035)$} & \multirow[t]{2}{*}{ Adjusted OR } & \multirow[t]{2}{*}{$95 \% \mathrm{Cl}$} & \multirow[t]{2}{*}{$\mathrm{p}$ value } \\
\hline & $\mathrm{n}$ & $\%$ & $\mathrm{n}$ & $\%$ & & & \\
\hline \multicolumn{8}{|l|}{ Seasonal vaccine } \\
\hline Yes & 146 & 21.3 & 304 & 29.7 & 0.78 & (o.61 to 0.99 ) & 0.048 \\
\hline No & 540 & 78.7 & 721 & 70.3 & \multicolumn{3}{|c|}{ Ref } \\
\hline \multicolumn{8}{|l|}{ Age } \\
\hline $18-64$ years & 386 & 55.8 & 422 & 40.8 & \multicolumn{3}{|c|}{ Ref } \\
\hline$\geq 65$ years & 306 & 44.2 & 613 & 59.2 & 0.56 & (0.45 to 0.68 ) & 0.001 \\
\hline \multicolumn{8}{|l|}{ Comorbidities } \\
\hline Yes & 520 & 75.1 & 765 & 73.9 & 1.36 & (1.07 to 1.73$)$ & 0.011 \\
\hline No & 172 & 24.9 & 270 & 26.1 & \multicolumn{3}{|c|}{ Ref } \\
\hline
\end{tabular}

$\mathrm{Cl}$ : confidence interval; ICU: intensive care unit; OR: odds ratio; Ref: reference.

we predicted the probability of influenza vaccination using the propensity score method. The propensity score was estimated by logistic regression with seasonal influenza vaccination as the outcome and age, sex, comorbidities, pregnancy, type of virus and antiviral treatment as independent variables. The propensity score was used as a continuous covariate in a final logistic regression model.

To assess the robustness of the estimate, influenza VE was also calculated in patient subgroups according to sex, age and antiviral treatment. The analysis was performed using the SPSS v.24 statistical package and the $\mathrm{R}$ v3.3.0 statistical software [18].

\section{Results}

A total of 1,727 patients aged 18 years and older hospitalised with severe laboratory-confirmed influenza were Included in the study, of which 736 (43.0\%) were female, 799 (46.7\%) were aged 18-64 years and 912 (53.3\%) were aged 65 years or older. In the six seasons studied (2010/11-2015/16), 1,470 (85.9\%) patients were infected with influenza $A$ viruses $\left(\mathrm{H}_{1} \mathrm{~N}_{1}=572\right.$ and $\left.\mathrm{H}_{3} \mathrm{~N}_{2}=572\right)$ and 241 (14.1\%) with influenza $B$ viruses. Of the 1,727 patients, 591 (34.2\%) were admitted to the ICU and 223 (12.9\%) died. A total of 1,285 (74.4\%) patients presented with one or more influenza risk factors, but only $450(26.1 \%)$ had received the influenza vaccine. Influenza vaccination uptake was similar in males and females (27.1\% vs $25.3 \%$ ) but higher in those aged 65 years or older compared with those aged $18-64$ years ( $41.6 \%$ vs $8.9 \%)$. There were 26 pregnant women, none of which were vaccinated (Table 1 ).

There were differences between patients admitted to the ICU or who died and those who did not. Patients who required ICU admission or died were more frequently male $(60.8 \%$ vs $54.4 \%, p<0.001)$, aged $18-64$ years $(55.8 \%$ vs $40.8 \%, p<0.001)$, obese $(12.6 \%$ vs
9.2\%, p $=0.02)$, immunodeficient $(23.0 \%$ vs $17.1 \%$ $\mathrm{p}<0.001)$, had chronic liver disease (8.4\% vs $5.5 \%$ $p=0.01)$, were pregnant $(2.3 \%$ vs $1 \% p=0.03)$ and $a$ higher proportion stayed in hospital more than 14 days ( $51.4 \%$ vs $17.0 \%, p<0.001$ ), but there were no differences in vaccinated patients vs unvaccinated patients in the average length of hospital stay $(14.11 \pm 15.58$ and $15.01 \pm 16.16$ days, respectively; $p=0.31)$, the type of virus or whether antiviral treatment was administered before or after 48 hours after hospital admission (Table 2).

Influenza vaccination uptake was lower in patients who required ICU admission or died (146/686: $21.3 \%$ vs 304/1025: 29.7\%, p <0.001) (Table 2). The unadjusted influenza VE in preventing ICU admission or death was $36 \%$ (95\% Cl: 20 to 49 ) and, except in one season $(2013 / 14)$, had a positive effect in all influenza seasons, although the effect was not significant in some seasons (2010/11, 2011/12, 2012/13 and 2013/14) (data not shown).

In the multivariable regression model, the variables associated with ICU admission or death were in those aged 65 years or older (aOR: $0.56 ; 95 \% \mathrm{Cl}: 0.45$ to 0.68 ) and comorbidities (aOR: $1.36 ; 95 \% \mathrm{Cl}: 1.07$ to 1.73 ). The adjusted effectiveness of influenza vaccination in preventing ICU admission or death was $22 \%$ (95\% $\mathrm{Cl}: 1$ to 39$)$ and remained the same after adjustment by the propensity score $(23 \% ; 95 \% \mathrm{Cl}: 1$ to 40 ) (Table 3 , propensity score data not shown). In the analysis restricted to sex, age group and antiviral treatment, influenza vaccination had a positive effect in all groups and categories, although in females and those aged 65 years and older, the effectiveness was lower and was not significant (Table 4). 


\section{TABLE 4}

Effect of seasonal influenza vaccination in reducing severity among subgroups of patients hospitalised due to laboratoryconfirmed influenza, Catalonia, Spain, influenza seasons 2010/11-2015/16 ( $=1727)$

\begin{tabular}{|c|c|c|c|c|c|c|c|}
\hline Analysis subset & ICU/death & Non-ICU/death & Crude vaccination effect & $95 \% \mathrm{Cl}$ & Adjusted vaccination effect (\%) & $95 \% \mathrm{Cl}$ & $p$-value \\
\hline \multicolumn{8}{|l|}{ Sex } \\
\hline Female & 271 & 472 & 27 & -5 to 49 & 3 & $\begin{array}{c}-43 \text { to } \\
34\end{array}$ & 0.886 \\
\hline Male & 421 & 563 & 43 & 22 to 57 & 33 & 8 to 51 & 0.014 \\
\hline \multicolumn{8}{|l|}{ Age } \\
\hline $18-64$ & 386 & 422 & 6 & $\begin{array}{c}-53 \text { to } \\
43\end{array}$ & 13 & $\begin{array}{c}-42 \text { to } \\
47\end{array}$ & 0.574 \\
\hline$\geq 65$ & 306 & 613 & 33 & -2 to 42 & 25 & -1 to 43 & 0.050 \\
\hline \multicolumn{8}{|l|}{ NI treatment } \\
\hline Yes & 635 & 942 & 36 & 18 to 49 & 21 & -2 to 39 & 0.070 \\
\hline No & 57 & 93 & 37 & $\begin{array}{c}-30 \text { to } \\
70\end{array}$ & 57 & 2 to 81 & 0.031 \\
\hline
\end{tabular}

$\mathrm{CI}$ : confidence interval; ICU: intensive care unit; NI: Neuraminidase inhibitors.

\section{Discussion}

This study, based on surveillance of hospitalised cases of severe laboratory-confirmed influenza from 2010/11-2015/16 in Catalonia, showed an effectiveness of influenza vaccination in reducing ICU admission or death of $23 \%$. Most patients presented with more than one influenza risk factor, but only $26.1 \%$ had received seasonal influenza vaccination, suggesting an important potential impact of vaccination in reducing influenza severity.

Our results are consistent with other studies, for example, a study conducted in the United States (US) by Catania et al. also found that patients requiring ICU admission had a lower influenza vaccination coverage [19]; A Spanish study by Casado et al. found that influenza vaccination was associated with a reduction in the odds of in-hospital death and ICU admission in adults hospitalised with laboratory-confirmed influenza [20]and a French study by Loubet et al. reported a reduction in the risk of ICU admission but not death in patients hospitalised with laboratory-confirmed influenza [21]. Our results and those of these studies, suggest that influenza vaccination is a factor for a good prognosis, as it reduces influenza-associated disease severity in patients, in whom vaccination did not prevent influenza.

A similar population-based study of patients hospitalised with laboratory-confirmed influenza by Arriola et al. conducted in the US during influenza season $2012 / 13$ [22] reported that $71 \%$ of patients were aged 65 years or older, $91 \%$ had medical conditions and $55 \%$ had been vaccinated. No association was found between influenza vaccination and ICU admission, death, pneumonia, or the length of hospital or ICU stay. However, after matching patients by the vaccination propensity score, they found that the length of ICU stay was reduced by a factor of $0.6(95 \% \mathrm{Cl}: 0.4$ to
0.8) among vaccinated 50-64 year olds compared with unvaccinated patients [22]. This is partly in line with our findings, as while we found a shorter length of hospital stay in vaccinated patients than in unvaccinated patients the difference was not statistically significant. Further, a study by Castilla et al. [23] also looking at hospitalised cases with laboratory-confirmed influenza found that vaccination protected against severe influenza (aOR: $0.42 ; 95 \% \mathrm{Cl}: 0.22$ to 0.80 ) and suggested that vaccination might be more effective in preventing severe than mild illness [23].

The influenza vaccination uptake in those aged 65 years and older in this study (41.6\%) was lower than that of the same age group in the Spanish general population (55.5\%) [24], and suggests that improving influenza vaccination coverages may have a noteworthy effect in reducing influenza severity.

Two main approaches are currently used to estimate the post-infection effects of vaccination. The first includes all studied individuals whether they become infected or not, and relies on of the following study designs: cohort, case-control or test-negative case-control. This approach enjoys the statistical validity associated with an intent-to-treat analysis and provides an assessment of the overall benefits of vaccination. However, such an approach does not distinguish between vaccine effects on susceptibility to infection and effects on the post infection endpoints of interest.

The second approach, which we used, includes only infected individuals and relies on a case-case study design. It uses the positive infection status to estimate the net effect of the vaccination on the post-infection endpoint. However, individuals that are infected, even though vaccinated, are unlikely to be identical to infected individuals that are unvaccinated and this 
can lead to biased interpretations. For example, a vaccine might better protect people with strong immune systems, so that infected vaccines tend to have weaker immune systems on average compared with infected unvaccinated cases. As a result, infected vaccinated persons could have worse post-infection outcomes on average than the infected controls due solely to selection bias and the estimate of VE in reducing severity could be underestimated [15].

As our study is based on a case-case analysis of patients hospitalized with severe laboratory-confirmed influenza, the vaccination effect should be attributed to the capacity to reduce severity after influenza infection had occurred. We do not know through which mechanisms vaccination prevents severity. While protection against influenza infection is primarily mediated by inducing antibodies, protection against severe influenza-related outcomes is mediated through the cellular immune responses affecting viral clearance $[25,26]$. Unlike antibodies, induced by rapidly mutating surface proteins, cell-mediated immunity to influenza is primarily induced by the major internal virus proteins that are generally more conserved across subtypes, allowing for greater heterologous cross-reactivity [27]. It is suggested that individuals previously infected by seasonal human influenza $A$ viruses or who received seasonal human influenza vaccines may derive benefits, at least in part, from the pre-existing cross-reactive memory of cytotoxic T lymphocytes in reducing the severity of $A\left(\mathrm{H}_{1} \mathrm{~N}_{1}\right)$ pdm infection, even without protective antibodies [25].

There were some mismatching seasons (2014/15 for influenza A virus and seasons 2011/12, 2013/14 and 2015/16 for influenza B virus) that may have had some influence on influenza VE.

\section{Strengths and limitations}

The strengths of the study include the large number of patients hospitalised for influenza, the multicentre design, uniform patient screening by hospitals, diagnostic confirmation of all patients and the extended study period of six consecutive influenza seasons (2010/11-2015/16).

The study also had some limitations. First, individuals aged 65 years and older may be less likely to be admitted to the ICU [28], which may have reduced the number of outcomes and the statistical power of the study. Second, although we included a number of potential confounders in the multivariate model, there might be unmeasured confounders associated with vaccination and severe influenza [29]. Third, as the likelihood of ICU admission was greater in those aged 64 and younger and the risk of death was greater in those aged 65 years and older, grouping of patients by these outcomes and age may have underestimated VE. For this reason, we also estimated the influenza VE in those aged 65 years and older, which was higher (25\%) than in people aged $18-64$ years (13\%). Other studies have applied this grouping of death and ICU admission as an outcome of influenza-associated disease severity $[21,23]$. Finally, physicians may have been more likely to test for influenza virus in patients presenting with more-severe ILI, underestimating the benefit of vaccination. However, as physicians were not aware of the vaccination status of patients it is unlikely that influenza vaccination produced a sampling bias. We only assessed in-hospital deaths we were unable to include deaths that occurred after discharge from hospital.

In conclusion, most patients hospitalised for severe influenza are aged 65 years and older and have underlying medical conditions, leading to a higher risk of influenza-associated complications, ICU admission and death. Influenza vaccination could reduce ICU admission and death in these patients, by reducing the severity of the disease. This effect complements the effectiveness of influenza vaccination in avoiding infection, especially in patients with underlying conditions, in whom influenza vaccination is frequently not optimal in preventing infection. Almost all the patients in this study qualified for influenza vaccination according to national guidelines [30]. Increased vaccination uptake might reduce the number of complications and ICU admissions. Annual influenza vaccination is still the best measure against influenza virus infection and its complications, particularly for populations at risk of more severe disease.

The Working Group on Surveillance of Severe Influenza Hospitalised Cases in Catalonia

Alsedà M, Álvarez J, Arias C, Balañà PJ, Barrabeig I, Camps $N$, Carol M, Ferràs J, Ferrús G, Follia N, Godoy P, Bach P, Jané M, Martínez A, Minguell S, Parrón I, Plasència E, SalaFarré MR, Torner N, Torra R, Torres J (Public Health Agency of Catalonia); Caylà J, Gorrindo P, Rius C (Public Health Agency of Barcelona); Marcos MA, Mosquera MDM, Vilella A (H Clínic, Barcelona); Antón A, Pumarola T, Campins M (H Universitari Vall d’Hebrón, Barcelona); García D (H Josep Trueta, Girona); Espejo E (H Terrassa); Freixas N, Riera Garcia M (Mútua Terrassa); Maraver E, Mas D, Perez R, (H Altahia Manresa); Rebull J (H.Verge de la Cinta, Tortosa); Pou J (H Sant Joan de Déu, Esplugues); García-Pardo G, Olona M (H Joan XXIII, Tarragona); Barcenilla F, Castellana D (H Arnau de Vilanova, Lleida) Navarro-Rubio G (Consorci Sanitari Parc Taulí, Sabadell); Force LL (H Mataró).

\section{Acknowledgements}

Funding: This study was funded by the Program of Surveillance, Prevention and Control of Transmissible Diseases (PREVICET) of CIBER de Epidemiología y Salud Pública (CIBERESP), Instituto de Salud Carlos III, Madrid and the Catalan Agency for the Management of Grants for University Research (AGAUR Grant Number 2017/SGR 1342).

Conflict of interest

None declared. 


\section{Authors' contributions}

Nuria Torner, Mireia Jané, Ana Martínez, Àngela Domínguez and Pere Godoy designed the study protocol. Joan Caylà, Cristina Rius, Nuria Torner, Mireia Jané, Ana Martínez and Pere Godoy organized the logistics. Joan Caylà, Cristina Rius, Nuria Torner, and Pere Godoy participated in the detection of cases, gathering epidemiological information and taking clinical samples and sending samples to the laboratory. Arantxa Romero, Núria Soldevila, Àngela Domínguez and Pere Godoy conducted the epidemiological and statistical analyses of the study. The authors in The Working Group on Surveillance of Severe Influenza Hospitalized Cases in Catalonia have participated in the detection of cases, gathering epidemiological information and taking clinical samples and sending samples to the laboratory. They have reviewed and approved the final version of the article. Pere Godoy made a first draft of the paper and all authors made relevant contributions to successive versions. All authors reviewed and approved the final version of the article.

\section{References}

1. World Health Organization (WHO). Influenza (Seasonal). Fact sheet. Geneva: WHO; 2016. Available from: http://www.who. int/mediacentre/factsheets/fs211/en/

2. World Health Organization (WHO). Global Epidemiological Surveillance Standards for Influenza. Geneva: WHO; 2014 Available from: http://www.who.int/influenza/resources documents/WHO_Epidemiological_Influenza_Surveillance_ Standards_2014.pdf?ua $=1$

3. Chaves SS, Aragon D, Bennett N, Cooper T, D'Mello T, Farley $M$, et al. Patients hospitalized with laboratory-confirmed influenza during the 2010-2011 influenza season: exploring disease severity by virus type and subtype. J Infect Dis. 2013;208(8):1305-14. https://doi.org/10.1093/infdis/jit316 PMID: 23863950

4. Ohmit SE, Thompson MG, Petrie JG, Thaker SN, Jackson ML, Belongia EA, et al. Influenza vaccine effectiveness in the 2011-2012 season: protection against each circulating virus and the effect of prior vaccination on estimates. Clin Infect Dis. 2014;58(3):319-27. https://doi.org/10.1093/cid/cit736 PMID: 24235265

5. McLean HQ, Thompson MG, Sundaram ME, Kieke BA, Gaglani $M$, Murthy K, et al. Influenza vaccine effectiveness in the United States during 2012-2013: variable protection by age and virus type. J Infect Dis. 2015;211(10):1529-40. https://doi. org/10.1093/infdis/jiu647 PMID: 25406334

6. Kissling E, Valenciano M, Buchholz U, Larrauri A, Cohen JM, Nunes B, et al. Influenza vaccine effectiveness estimates in Europe in a season with three influenza type/subtypes circulating: the I-MOVE multicentre case-control study, influenza season 2012/13. Euro Surveill. 2014:19(6):20701. https://doi.org/10.2807/1560-7917.ES2014.19.6.20701 PMID: 24556348

7. Valenciano M, Kissling E, Reuss A, Rizzo C, Gherasim A, Horváth JK, et al. Joan O'Donell; I-MOVE multicentre casecontrol team. Vaccine effectiveness in preventing laboratoryconfirmed influenza in primary care patients in a season of co-circulation of influenza $A\left(\mathrm{H}_{1} \mathrm{~N}_{1}\right)$ pdmog, $B$ and drifted A(H32), I-MOVE Multicentre Case-Control Study, Europe 2014/15. Euro Surveill. 2016;21(7):30139. https://doi. org/10.2807/1560-7917.ES.2016.21.7.30139 PMID: 26924024

8. Turner N, Pierse N, Bissielo A, Huang Q, Radke S, Baker M, et al. SHIVERS investigation team. Effectiveness of seasonal trivalent inactivated influenza vaccine in preventing influenza hospitalisations and primary care visits in Auckland, New Zealand, in 2013. Euro Surveill. 2014;19(34):20884. https:// doi.org/10.2807/1560-7917.ES2014.19.34.20884 PMID: 25188614

9. Sullivan SG, Cowling BJ, Greenland S. Frailty and influenza vaccine effectiveness. Vaccine. 2016;34(39):4645-6. https:// doi.org/10.1016/j.vaccine.2016.08.003 PMID: 27578296

10. Weinberger B, Herndler-Brandstetter D, Schwanninger A, Weiskopf D, Grubeck-Loebenstein B. Biology of immune responses to vaccines in elderly persons. Clin Infect Dis. 2008;46(7):1078-84. https://doi.org/10.1086/529197 PMID: 18444828

11. He XS, Holmes TH, Sanyal M, Albrecht RA, García-Sastre A, Dekker CL, et al. Distinct patterns of B-cell activation and priming by natural influenza virus infection versus inactivated influenza vaccination. J Infect Dis. 2015;211(7):1051-9. https:// doi.org/10.1093/infdis/jiu580 PMID: 25336731

12. Gilca R, De Serres G, Boulianne N, Ouhoummane N, Papenburg J, Douville-Fradet $M$, et al. Risk factors for hospitalization and severe outcomes of 2009 pandemic $\mathrm{H}_{1} \mathrm{~N}_{1}$ influenza in Quebec, Canada. Influenza Other Respi Viruses. 2011;5(4):24755. https://doi.org/10.1111/j.1750-2659.2011.00204.x PMID: 21651735

13. McLean HQ, Meece JK, Belongia EA. Influenza vaccination and risk of hospitalization among adults with laboratory confirmed influenza illness. Vaccine. 2014:32(4):453-7. https://doi. org/10.1016/j.vaccine.2013.11.060 PMID: 24291201

14. Ridenhour BJ, Campitelli MA, Kwong JC, Rosella LC, Armstrong BG, Mangtani P, et al. Effectiveness of inactivated influenza vaccines in preventing influenza-associated deaths and hospitalizations among Ontario residents aged $\geq 65$ years: estimates with generalized linear models accounting for healthy vaccinee effects. PLoS One. 2013;8(10):e76318. https://doi.org/10.1371/journal.pone.0076318 PMID: 24146855

15. Hudgens MGMEH, Halloran ME. Causal Vaccine Effects on Binary Postinfection Outcomes. J Am Stat Assoc. 2006;101(473):51-64. https://doi. org/10.1198/016214505000000970 PMID: 19096723

16. Torner N, Martínez A, Basile L, Plasencia E, Barrabeig I, Follia N, et al. Vigilància epidemiològica dels casos greus hospitalitzats confirmats de grip. Xarxa sentinella PIDIRAC (Catalunya 2010-2015) [Epidemiological surveillance of confirmed hospitalized severe cases of flu. PIDIRAC sentinel network (Catalunya 2010-2015)]. Butlletí Epidemiol Catalunya [Epidemiological bulletin of Catalonia]. 2016;37:234-53. [Spanish]. Available from: http://canalsalut. gencat.cat/ca/actualitat/llista_butlletins/salut_publica/ butlleti_epidemiologic_de_catalunya/

17. European Commission. Commission Regulation (EC) No 2018/945 of 22 June 2018 on the communicable diseases and related special health issues to be covered by epidemiological surveillance as well as relevant case definitions. Official Journal of the European Union. 6.7.2018:L 170/1. Available from: https://eur-lex.europa.eu/legal-content/EN/TXT/PDF/?uri $=$ CELEX:32018D 0945\&from $=$ EN\#page $=24$

18. The R Project for Statistical Computing (R). The comprehensive R Archive Network. R; 2018. Available from: http://cran.rproject.org

19. Catania J, Que LG, Govert JA, Hollingsworth JW, Wolfe CR. High intensive care unit admission rate for 2013-2014 influenza is associated with a low rate of vaccination. Am J Respir Crit Care Med. 2014;189(4):485-7. https://doi.org/10.1164/rccm.2014010066LE PMID: 24512430

20. Casado I, Domínguez A, Toledo D, Chamorro J, Force L, Soldevila $\mathrm{N}$, et al. Effect of influenza vaccination on the prognosis of hospitalized influenza patients. Expert Rev Vaccines. 2016;15(3):425-32. PMID: 26690376

21. Loubet P, Samih-Lenzi N, Galtier F, Vanhems P, Loulergue P, Duval X, et al. Factors associated with poor outcomes among adults hospitalized for influenza in France: A three-year prospective multicenter study. J Clin Virol. 2016;79:68-73. https://doi.org/10.1016/j.jcv.2016.04.005 PMID: 27105315

22. Arriola CS, Anderson EJ, Baumbach J, Bennett N, Bohm S, Hill $M$, et al. Does influenza vaccination modify influenza severity? Data on older adults hospitalized with influenza during the 2012-2013 season in the United States. J Infect Dis. 2015;212(8):1200-8. https://doi.org/10.1093/infdis/jiv200 PMID: 25821227

23. Castilla J, Navascués A, Fernández-Alonso M, Reina G, Albéniz E, Pozo F, et al. Effects of previous episodes of influenza and vaccination in preventing laboratory-confirmed influenza in Navarre, Spain, 2013/14 season. Euro Surveill. 2016;20(22):30243. https://doi.org/10.2807/1560-7917. ES.2016.21.22.30243 PMID: 27277013

24. Ministerio de Sanidad, Consumo y Bienestar Social. Tabla 13. Evolución de cobertura de vacunación antigripal en población $\geq 65$ años. España, temporadas 2008-2009 a 2017-2018. [Table 13. Evolution of coverage of influenza vaccination in population $\geq 65$ years. Spain, seasons 2008-2009 to 2017 2018]. Madrid: Gobierno de España [Government of Spain]; 2018. Spanish. Available from: https://www.mscbs.gob.es/ profesionales/saludPublica/prevPromocion/vacunaciones/ docs/CoberturasVacunacion/Tabla13.pdf

25. Thomas PG, Keating R, Hulse-Post DJ, Doherty PC. Cellmediated protection in influenza infection. Emerg Infect Dis. 2006;12(1):48-54. https://doi.org/10.3201/eid1201.051237 PMID: 16494717

26. Tu W, Mao H, Zheng J, Liu Y, Chiu SS, Qin G, et al. Cytotoxic T lymphocytes established by seasonal human influenza crossreact against 2009 pandemic $\mathrm{H}_{1} \mathrm{~N}_{1}$ influenza virus. J Virol. 2010;84(13):6527-35. https://doi.org/10.1128/JVI.00519-10 PMID: 20410263 
27. Skowronski DM, Hottes TS, McElhaney JE, Janjua NZ, Sabaiduc $\mathrm{S}$, Chan T, et al. Immuno-epidemiologic correlates of pandemic H1N1 surveillance observations: higher antibody and lower cell-mediated immune responses with advanced age. J Infect Dis. 2011;203(2):158-67. https://doi.org/10.1093/infdis/jiq039 PMID: 21288814

28. Chan MC, Lee N, Ngai KL, Leung TF, Chan PK. Clinical and virologic factors associated with reduced sensitivity of rapid influenza diagnostic tests in hospitalized elderly patients and young children. J Clin Microbiol. 2014;52(2):497-501. https:// doi.org/10.1128/JCM.02316-13 PMID: 24478479

29. Cromer D, van Hoek AJ, Jit M, Edmunds WJ, Fleming D, Miller $E$. The burden of influenza in England by age and clinical risk group: a statistical analysis to inform vaccine policy. J Infect. 2014;68(4):363-71. https://doi.org/10.1016/j.jinf.2013.11.013 PMID: 24291062

30. Mereckiene J, Cotter S, Nicoll A, Lopalco P, Noori T, Weber J, et al. VENICE project gatekeepers group. Seasonal influenza immunisation in Europe. Overview of recommendations and vaccination coverage for three seasons: pre-pandemic (2008/09), pandemic (2009/10) and post-pandemic (2010/11). Euro Surveill. 2014;19(16):20780. https://doi. org/10.2807/1560-7917.ES2014.19.16.20780 PMID: 24786262

\section{License and copyright}

This is an open-access article distributed under the terms of the Creative Commons Attribution (CC BY 4.0) Licence. You may share and adapt the material, but must give appropriate credit to the source, provide a link to the licence, and indicate if changes were made.

This article is copyright of the authors, 2018. 